Check for updates

Cite this: Chem. Sci., 2019, 10, 10436

๑ All publication charges for this article have been paid for by the Royal Society of Chemistry

\title{
Activating the surface and bulk of hematite photoanodes to improve solar water splitting $\dagger$
}

\author{
Hemin Zhang, (D) a Jong Hyun Park, ${ }^{b}$ Woo Jin Byun, ${ }^{a}$ Myoung Hoon Song (D) ${ }^{b}$ \\ and Jae Sung Lee $\mathbb{D}$ *a
}

A simple electrochemical activation treatment is proposed to improve effectively the photoelectrochemical performance of $\mathrm{Nb}, \mathrm{Sn}$ co-doped hematite nanorods. The activation process involves an initial thrice cathodic scanning (reduction) and a subsequent thrice anodic scanning (oxidation), which modifies both the surface and bulk properties of the $\mathrm{Nb}, \mathrm{Sn}: \mathrm{Fe}_{2} \mathrm{O}_{3}$ photoanode. First, it selectively removes the surface components to different extents endowing the hematite surface with fewer defects and richer $\mathrm{Nb}-\mathrm{O}$ and $\mathrm{Sn}-\mathrm{O}$ bonds and thus passivates the surface trap states. The surface passivation effect also enhances the photoelectrochemical stability of the photoanode. Finally, more $\mathrm{Fe}^{2+}$ ions or oxygen vacancies are generated in the bulk of hematite to enhance its conductivity. As a result, the photocurrent density is increased by $62.3 \%$ from 1.88 to $3.05 \mathrm{~mA} \mathrm{~cm}^{-2}$ at $1.23 \mathrm{~V}_{\mathrm{RHE}}$, the photocurrent onset potential shifts cathodically by $\sim 70 \mathrm{mV}$, and photoelectrochemical stability improves remarkably relative to the pristine photoanode under simulated sunlight $\left(100 \mathrm{~mW} \mathrm{~cm}^{-2}\right)$.

Received 17th August 2019

Accepted 30th September 2019

DOI: $10.1039 /$ c9sc04110a

rsc.li/chemical-science vacancies $\left(V_{\mathrm{O}}\right)$ are effective to improve its conductivity by enhancing the charge carrier density. ${ }^{4,5}$ Surface engineering can effectively overcome its large overpotential and low photocurrent density problems by removing the surface states through introducing a passivation layer and loading a co-catalyst. ${ }^{6-8}$

In addition to these traditional modification strategies, some post-synthetic treatments can also significantly improve the performance of photoanodes for PEC water splitting. For example, Zou et al. reported a surface corrosion method in acid solution to reduce the overpotential of $\mathrm{Ti}^{4+}$-doped hematite by suppressing the back reaction. ${ }^{9}$ Li et al. reported an acid treatment method to improve the photocurrent density by suppressing electron-hole recombination in $\mathrm{Sn}^{4+}$-doped hematite. ${ }^{10}$ Jang et al. reported a re-growth strategy to reduce surface disorders of $\mathrm{NiFeO}_{x}$-loaded hematite to achieve an onset voltage $\left(V_{\text {on }}\right)$ of $0.45 \mathrm{~V}$ ( $v s$. the reversible hydrogen electrode, RHE). ${ }^{6}$ It was also reported that the PEC performance of $\mathrm{BiVO}_{4}$ was improved by ultraviolet irradiation ${ }^{\mathbf{1 1}}$ and electrochemical treatments. ${ }^{12}$ Herein, we demonstrate a simple electrochemical process involving repeated reduction/oxidation to enhance the PEC performance of a $\mathrm{Nb}, \mathrm{Sn}$ co-doped hematite nanorod (Nb,Sn: $\mathrm{Fe}_{2} \mathrm{O}_{3} \mathrm{NR}$ ) photoanode.

\section{Results and discussion}

\subsection{Synthesis and characterization of $\mathrm{Nb}, \mathrm{Sn}$ co-doped hematite nanorods}

Scheme 1 shows schematics of the synthesis and electrochemical activation process of small Nb,Sn: $\mathrm{Fe}_{2} \mathrm{O}_{3}$ NRs synthesized on $\mathrm{F}: \mathrm{SnO}_{2}$ (FTO) glass substrates according to our 


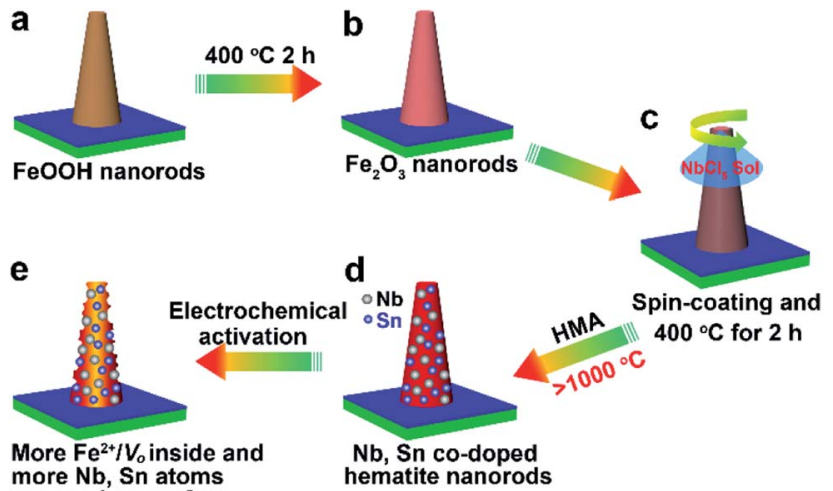

more $\mathrm{Nb}, \mathrm{Sn}$ atoms

exposed on surface

Scheme 1 Synthesis and electrochemical activation process of a $\mathrm{Nb}, \mathrm{Sn}: \mathrm{Fe}_{2} \mathrm{O}_{3} \mathrm{NR}$ photoanode.

previously reported method. .3,14 $^{\mathbf{1}}$ brief, ultrathin $\mathrm{FeOOH}$ nanorods are first grown on FTO by a hydrothermal method and turned into amorphous hematite nanorods at $400{ }^{\circ} \mathrm{C}$ for $2 \mathrm{~h}$. Then, a low concentration of $\mathrm{NbCl}_{5}$ solution is spin-coated and the second heating follows under the same conditions. Subsequently, hybrid microwave annealing (HMA) treatment is adopted to take advantage of its unique characteristics: (i) reaching extremely high temperature in a very short time of a few minutes, (ii) preserving original nanoscale morphology under harsh fabrication conditions, and (iii) negligible damage of FTO substrates at a high temperature. These features of HMA are highly beneficial for the fabrication of efficient photoelectrodes, which the conventional thermal annealing cannot provide. Finally, the synthesized photoelectrode is electrochemically activated through an initial thrice cathodic scanning (reduction) and a subsequent thrice anodic scanning (oxidation). As discussed below, the activation treatment modifies both the bulk and surface properties of $\mathrm{Nb}, \mathrm{Sn}: \mathrm{Fe}_{2} \mathrm{O}_{3} \mathrm{NRs}$, leading to markedly enhanced PEC performance.

Our previous reports demonstrated that all the spin-coated $\mathrm{Nb} / \mathrm{Ta}$ atoms were incorporated into the hematite lattice by the highly effective HMA. ${ }^{13,14}$ Simultaneously, Sn atoms would also diffuse into the hematite lattice from the bottom FTO substrate to complete the fabrication of $\mathrm{Nb}$,Sn co-doped $\mathrm{Fe}_{2} \mathrm{O}_{3}$ nanorods. Electron energy loss spectroscopy (EELS) mapping (Fig. 1a-e) gives the spatial distribution of elements in hematite NRs, indicating that $\mathrm{Fe}, \mathrm{O}$ and $\mathrm{Nb}$ are uniformly distributed in the whole nanorod and $\mathrm{Sn}$ has a little gradient from bottom (FTO source) to top. Furthermore, a high-angle annular dark-field scanning transmission electron microscopy (HAADF-STEM) image (Fig. 1f) shows many bright atoms (circled), which must be the external doping atoms of $\mathrm{Nb}$ and $\mathrm{Sn}$. Note that there are no attached nanoparticles on the nanorod surface, which
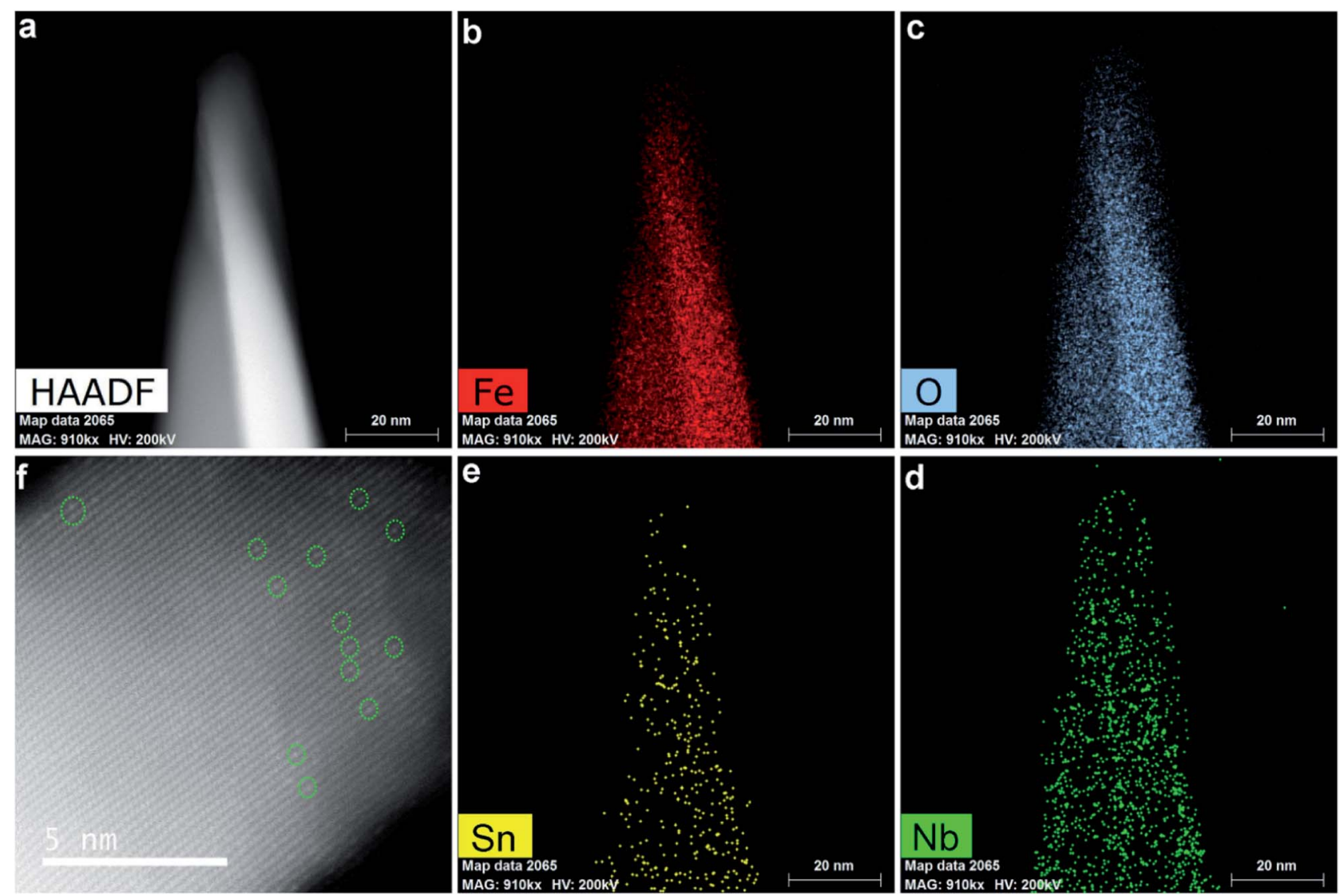

Fig. 1 STEM (a), corresponding EDX mapping ((b-e), Fe, O, Nb and Sn, respectively) and high-resolution HAADF-STEM (f) images of the synthesized $\mathrm{Nb}, \mathrm{Sn}$ co-doped hematite nanorods. 
demonstrates that all the spin-coated $\mathrm{Nb}$ atoms have been diffused into hematite lattices. Besides, the corresponding energy dispersive X-ray spectrum (EDX) shows that the concentrations of $\mathrm{Nb}$ and $\mathrm{Sn}$ in hematite NRs are 0.9 at\% and 0.4 at\%, respectively (Fig. S1, ESI $\dagger$ ). The inductively coupled plasma optical emission spectrometry (ICP-OES) results demonstrate $5.5 \mathrm{wt} \% \mathrm{Nb}$ (Fig. S2 $\dagger$ ), which agrees well with 0.9 at $\% \mathrm{Nb}(\sim 5.2 \mathrm{wt} \%)$ by TEM-EDX. The electrochemical activation process proposed here involves a thrice cathodic linear scanning followed by another thrice anodic linear scanning (detailed information in Fig. S3†). The treatment was conducted in $1 \mathrm{M} \mathrm{KOH}$ solution in the dark using a three-electrode cell with the $\mathrm{Nb}, \mathrm{Sn}: \mathrm{Fe}_{2} \mathrm{O}_{3} \mathrm{NR}$ photoanode, $\mathrm{Ag} / \mathrm{AgCl}(3 \mathrm{M} \mathrm{NaCl})$, and Pt mesh as working, reference, and counter electrodes, respectively. The simple electrochemical process involving repeated reduction and oxidation enhances the PEC performance of the photoanode by modifying both the surface and bulk properties of hematite as detailed below.

Scanning electron microscope (SEM) images show no change in morphological features before (Fig. 2a) and after (Fig. 2b) the electrochemical treatment, both showing small nanorods with diameters of 20-50 $\mathrm{nm}$. The activated sample also has a smooth surface similar to the pristine sample, and comparable surface areas measured using the adsorbed methylene blue dye (Fig. S4 $\dagger$ ). The X-ray diffraction (XRD) pattern after the activation treatment does not show any decreased peak intensities or shifted peak positions (Fig. 2c). Besides, Nb,Sn: $\mathrm{Fe}_{2} \mathrm{O}_{3}$ shows a little smaller diameter (increased full width at half maximum) and positive peak shifts relative to only Sn-doped hematite (Fig. $\mathrm{S} 5 \dagger$ ), indicating that $\mathrm{Nb}$ atoms from the surface coating are effectively doped into the hematite lattice while preserving the original nanostructure. Moreover, absorption spectra before and after the treatment are nearly superimposable (Fig. 2d), thus ruling out any change in light harvesting capability by the activation process. High resolution transmission electron microscopy (HRTEM) images show that there are many defects (including dangling bonds, amorphous state $\mathrm{Fe}_{2} \mathrm{O}_{3}$, interstitial and vacancy defects) found on the surface of the hematite nanorod before activation (highlighted in Fig. 2e). In contrast, the surface is much cleaner after the activation (Fig. 2f), indicating that a type of etching takes place during the process. Both samples show well-defined HRTEM lattice fringes denoting preferential orientation of [012], indicating that the electrochemical activation does not change the high crystallinity induced by HMA, which is consistent with the XRD results.

\subsection{Effects of the activation treatment on the surface and bulk properties of hematite}

Surface-sensitive X-ray photoelectron spectroscopy (XPS) was combined with $\mathrm{Ar}^{+}$etching to investigate the depth-dependent compositions of $\mathrm{Nb}, \mathrm{Sn}: \mathrm{Fe}_{2} \mathrm{O}_{3}$ photoanodes before and after the activation treatment. It should be noted that $300 \mathrm{~s}$ operation in our depth profiling achieves $\sim 5 \mathrm{~nm}$ surface etching, which was estimated with a planar hematite film (synthesized by HMA) on silicon substrates. When the etching time exceeds $300 \mathrm{~s}$, the intensity of the $\mathrm{Nb} 3 \mathrm{~d}$ spectrum of the as-prepared $\mathrm{Nb}, \mathrm{Sn}: \mathrm{Fe}_{2} \mathrm{O}_{3}$ nanorod sample begins to decrease. As shown in Fig. $3 \mathrm{a}_{0}-\mathrm{d}_{0}$, there is almost no difference in XPS spectra of the pristine $\mathrm{Nb}, \mathrm{Sn}: \mathrm{Fe}_{2} \mathrm{O}_{3}$ NRs before and after surface etching for $300 \mathrm{~s}$ (except that $\mathrm{Fe} 2 \mathrm{p}$ and $\mathrm{O}$ 1s show a very limited decrease of intensity), demonstrating that the as-synthesized $\mathrm{Nb}, \mathrm{Sn}: \mathrm{Fe}_{2} \mathrm{O}_{3}$ NRs by HMA are homogeneous in composition from the surface
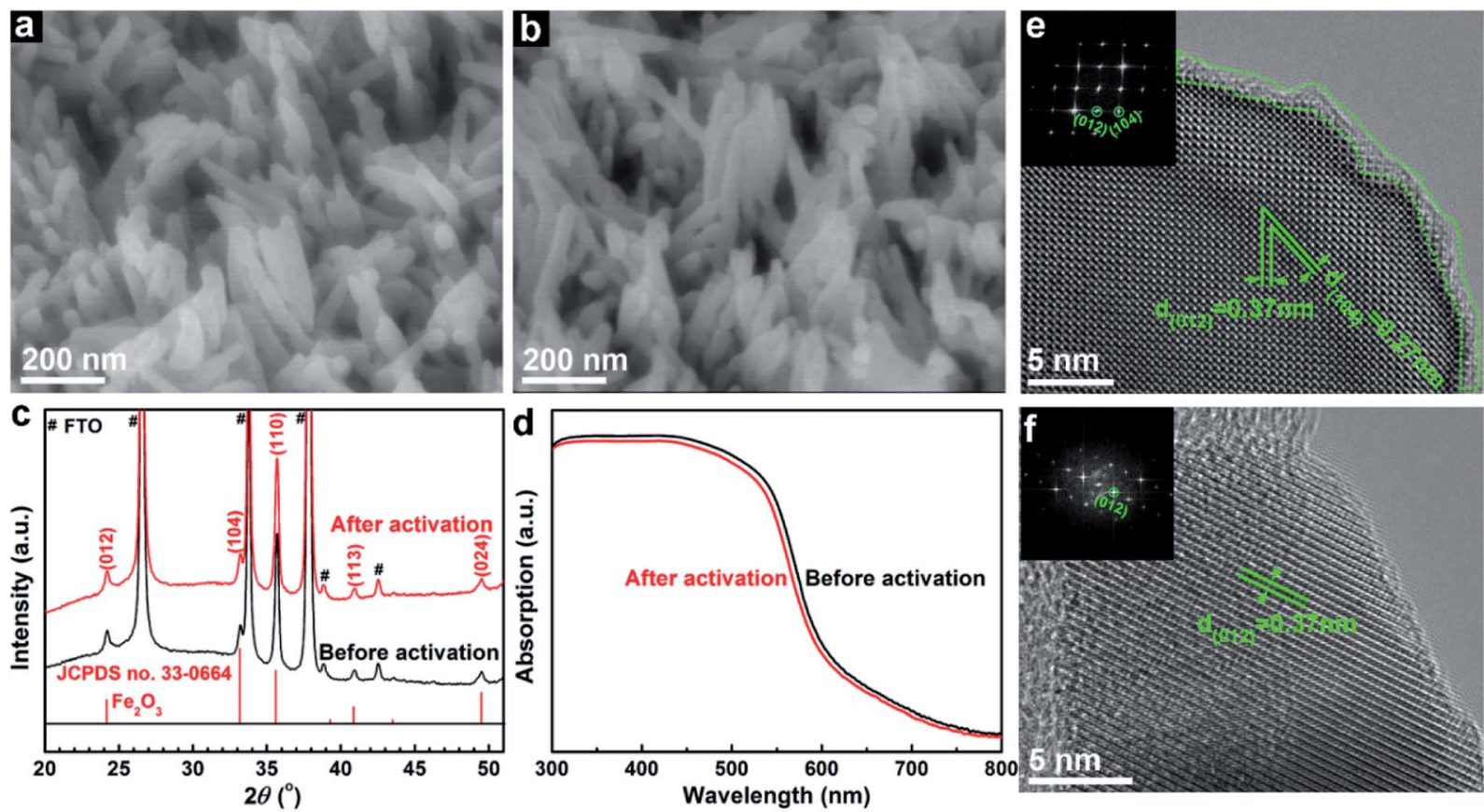

Fig. 2 SEM images ((a), before; (b), after), XRD (c) and UV-vis spectra (d) HRTEM (e and f) of the hematite photoanode before and after the electrochemical activation treatment. Insets (e and f) show the corresponding fast Fourier transform diffraction patterns (FFTs). 
(before etching) to bulk (after etching) of the hematite. In contrast, the activated photoanode in Fig. $3 \mathrm{a}_{1}-\mathrm{d}_{1}$ shows significant differences. Upon etching, the intensity of Fe $2 \mathrm{p}$ and $\mathrm{O} 1 \mathrm{~s}$ spectra decreases by $41.6 \%$ and $28.3 \%$, while that of $\mathrm{Nb} 3 \mathrm{~d}$ and Sn $3 \mathrm{~d}$ spectra increases by $2.8 \%$ and $1.6 \%$, respectively, which demonstrates that the activation process selectively removes the surface components of $\mathrm{Nb}, \mathrm{Sn}: \mathrm{Fe}_{2} \mathrm{O}_{3}$ to a different extent. As shown in Fig. S6, $\uparrow$ the varied intensity was calculated from the integrated XPS peak areas. Thus, the activation treatment selectively removes $\mathrm{Fe}$ from the surface, which reflects its weakest bond energy: $D_{298}^{\mathrm{o}} / \mathrm{kJ} \mathrm{mol}^{-1}=\mathrm{Fe}-\mathrm{O}(407)<\mathrm{Sn}-\mathrm{O}(528)<$ $\mathrm{Nb}-\mathrm{O}(726) .{ }^{15}$ As a result, more $\mathrm{Nb}$ and $\mathrm{Sn}$ atoms remain on the surface than in the bulk after the treatment.

The electrochemical activation treatment brings another significant change in Fe 2p spectra (Fig. 3a $\mathrm{a}_{1}$ ). Both pristine and activated $\mathrm{Nb}, \mathrm{Sn}: \mathrm{Fe}_{2} \mathrm{O}_{3}$ samples show Fe 2 $\mathrm{p}_{3 / 2}(\sim 711.2 \mathrm{eV})$ and $\mathrm{Fe}$ $2 \mathrm{p}_{1 / 2}(\sim 724.8 \mathrm{eV})$ peaks as typical for $\mathrm{Fe}^{3+}$ in $\mathrm{Fe}_{2} \mathrm{O}_{3} \cdot{ }^{16}$ However, the surface of the activated sample shows a satellite peak of $\mathrm{Fe}^{3+}$ at $719.3 \mathrm{eV}$, which disappears after $\sim 5 \mathrm{~nm}$ etching indicating the presence of more $\mathrm{Fe}^{2+}$ ions or $V_{\mathrm{O}}$ in the bulk of activated $\mathrm{Nb}, \mathrm{Sn}: \mathrm{Fe}_{2} \mathrm{O}_{3}$ compared with the pristine sample (Fig. $3 \mathrm{a}_{0}$ ). In $\mathrm{O}$ 1s spectra (Fig. $3 \mathrm{~b}_{1}$ ), the surface of the activated sample exhibits a notable shoulder peak (dot circled) in the range of 531.9-533.7
eV, which can be attributed to defect sites, e.g. dangling oxo or hydroxyl groups usually observed around $\sim 532.0 \mathrm{eV}$ (ref. 17) and chemisorbed oxygen at 532.4-533.7 eV. ${ }^{18}$ This peak is not observed in the bulk after $\sim 5 \mathrm{~nm}$ etching. Fig. $3 \mathrm{c}_{1}$ displays typical peaks of $\mathrm{Nb} 3 \mathrm{~d}_{5 / 2}$ at $\sim 206.2 \mathrm{eV}$ and $\mathrm{Nb} 3 \mathrm{~d}_{3 / 2}$ at $\sim 209.0 \mathrm{eV}$ due to $\mathrm{Nb}^{5+}$, both on the surface and in the bulk. Besides, the binding energy of $\mathrm{Nb} 3 \mathrm{~d}_{5 / 2}$ is between $\mathrm{Nb}_{2} \mathrm{O}_{5}(207.1 \mathrm{eV})$ and metallic $\mathrm{Nb}(202.4 \mathrm{eV})$, suggesting that $\mathrm{Nb}^{5+}$ ions are indeed doped into the $\mathrm{Fe}_{2} \mathrm{O}_{3}$ lattice. ${ }^{19}$ The $\mathrm{Sn} 3 \mathrm{~d}$ spectra in Fig. $3 \mathrm{~d}_{1}$ exhibit two peaks centred at $486.4 \mathrm{eV}$ for $\mathrm{Sn} 3 \mathrm{~d}_{5 / 2}$ and $494.8 \mathrm{eV}$ for $S n 3 d_{3 / 2}$. The binding energy of $S n 3 d_{5 / 2}$ is between the typical values for $\mathrm{SnO}_{2}(486.6 \mathrm{eV})$ and metallic $\mathrm{Sn}(484.6 \mathrm{eV})$, indicating that the $\mathrm{Sn}^{4+}$ dopants are also incorporated into the hematite lattice. ${ }^{20}$ The change in the surface and bulk elemental structure before and after the electrochemical activation is schematically illustrated in Fig. S7. $\dagger$ Considering that the profiling depth of the pristine sample may not be deep enough due to the reduced thickness of the surface amorphous layer by activation, we extended the depth profiling time further to 400 and $500 \mathrm{~s}$ for the pristine sample (Fig. S8 $\dagger$ ). All the elements maintained exactly the same signals but with decreased intensities, which further demonstrates the homogeneous composition of the pristine sample from outside to inside.
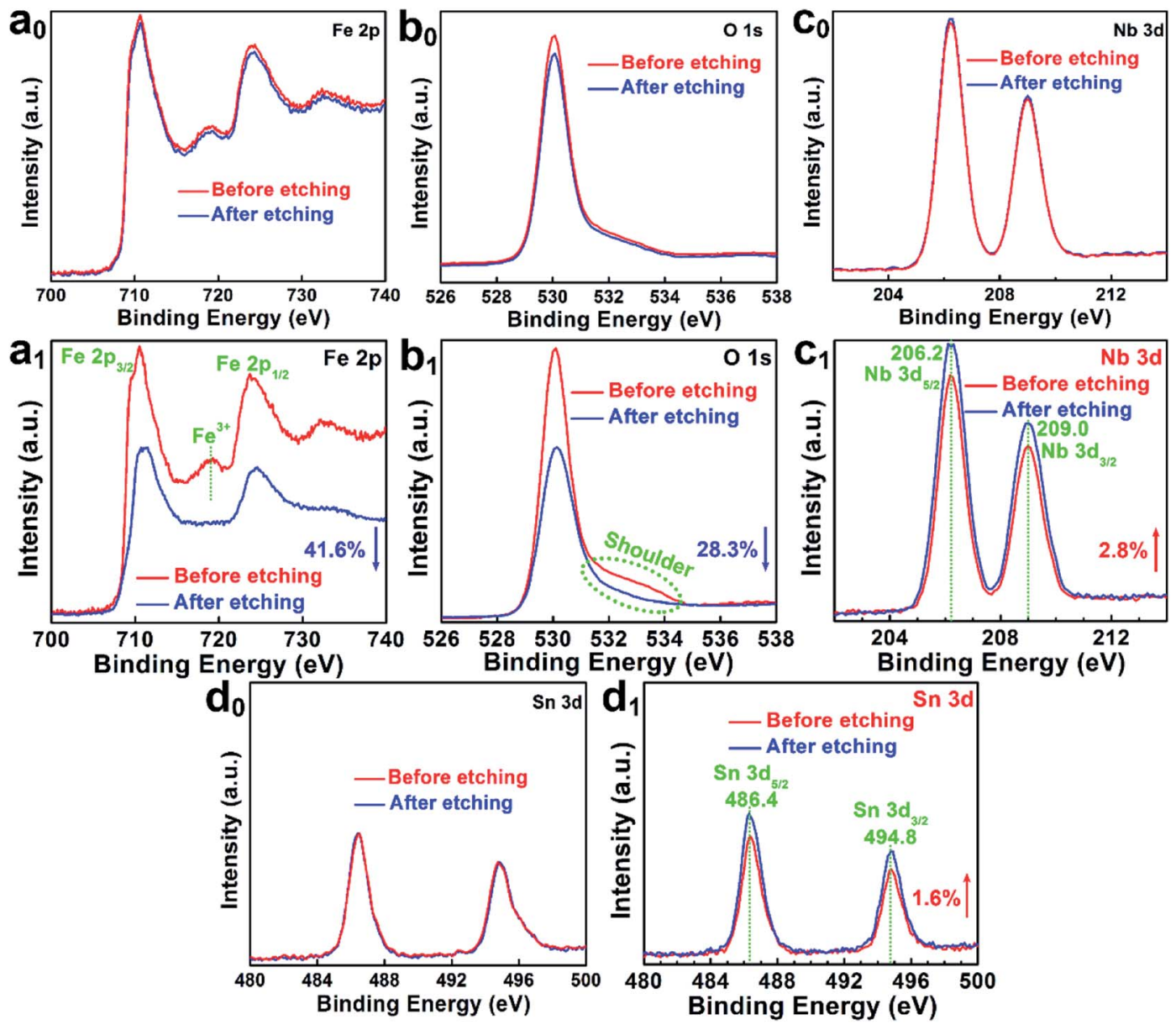

Fig. 3 XPS spectra of the pristine and activated $\mathrm{Nb}, \mathrm{Sn}: \mathrm{Fe}_{2} \mathrm{O}_{3}$ photoanode before and after surface etching ( $\left.5 \mathrm{~nm}\right)$, respectively. ( $\mathrm{a}_{0}$ and $\left.\mathrm{a}_{1}\right)$ Fe 2p. $\left(b_{0}\right.$ and $\left.b_{1}\right) O$ 1s. $\left(c_{0}\right.$ and $\left.c_{1}\right) N b 3 d .\left(d_{0}\right.$ and $\left.d_{1}\right)$ Sn 3d. 


\subsection{Effects on photoelectrochemical water oxidation performance}

After the electrochemical activation, the photocurrent density of PEC water oxidation reaches $3.05 \mathrm{~mA} \mathrm{~cm}^{-2}$ at $1.23 \mathrm{~V}_{\mathrm{RHE}}$ in $1 \mathrm{M}$ $\mathrm{KOH}$ electrolyte under 1 sun $\left(100 \mathrm{~mW} \mathrm{~cm}^{-2}\right)$ irradiation, which is significantly higher (by $62.3 \%$ ) than that of the pristine photoanode $\left(1.88 \mathrm{~mA} \mathrm{~cm}^{-2}\right)$ as shown in Fig. 4a. More significantly, the photocurrent onset potential $\left(V_{\text {on }}\right)$ exhibited a modest cathodic shift of $\sim 70 \mathrm{mV}$, which was also similar to the shift $(\sim 50 \mathrm{mV})$ estimated by the first order derivative of the photocurrent density against the voltage ${ }^{21}$ (Fig. S9†). The modest shift of $V_{\text {on }}$ should be related to the extremely thin surface passivation layer (only rich $\mathrm{Nb}-\mathrm{O}$ and $\mathrm{Sn}-\mathrm{O}$ bonds), which might not be a continuous layer and cannot accumulate many photoexcited holes on the surface. The measured photovoltage (Fig. S10†) also shows $\sim 40 \mathrm{mV}$ increase from $160 \mathrm{mV}$ (pristine) to $200 \mathrm{mV}$ (after activation), which are consistent with previously reported values. ${ }^{22}$ It should be emphasized that the results were highly reproducible, which was consistently observed for the other repeated samples (Table S1†). By comparison, the pristine sample with a lower photocurrent exhibited a tendency to show a little higher extent of improvement after the activation. In fact, the activation process causes a little decreased surface area by $2.6 \%$ (Fig. $\mathrm{S} 4 \dagger$ ) by removal of some defective/amorphous part of hematite as indicated by HRTEM images in Fig. 1 and the XPS results in Fig. 3. In addition, the corresponding dark current of the water oxidation reaction is suppressed after the activation (inset of Fig. 4a). This behaviour implies a lower electrocatalytic activity, which was also observed in previous reports on acidtreated, doped-hematite and UV light-treated $\mathrm{BiVO}_{4} \cdot{ }^{9-11}$ Obviously, the reduced surface area and the lower catalytic activity would not have contributed to the improved PEC performance in any positive manner. Then how does the activation
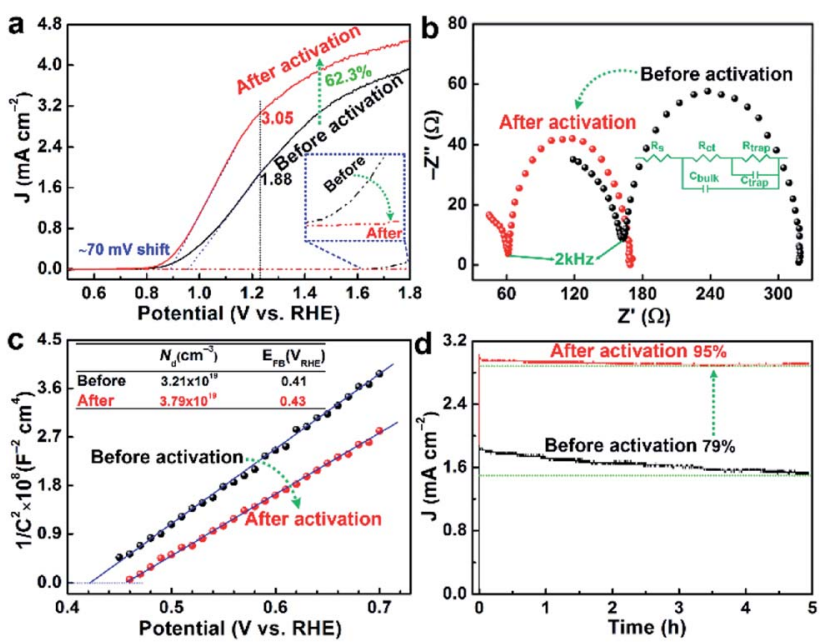

Fig. 4 Dark current (dashed) and photocurrent (solid) densities of PEC water oxidation in $1 \mathrm{M} \mathrm{KOH}$ electrolyte under 1 sun $\left(100 \mathrm{~mW} \mathrm{~cm}^{-2}\right)$ irradiation (a), Nyquist plots of EIS (b), Mott-Schottky plots (c) and stability tests (d) of the $\mathrm{Nb}, \mathrm{Sn}: \mathrm{Fe}_{2} \mathrm{O}_{3}$ photoanode before and after the activation treatment. treatment enhance the PEC performance of the $\mathrm{Nb}, \mathrm{Sn}: \mathrm{Fe}_{2} \mathrm{O}_{3}$ photoanode?

As discussed, XPS combined with etching demonstrates that the activated $\mathrm{Nb}, \mathrm{Sn}: \mathrm{Fe}_{2} \mathrm{O}_{3}$ shows more $\mathrm{Fe}^{2+}$ ions or $V_{\mathrm{O}}$ in the bulk (etched surface) relative to the pristine photoanode (Fig. 3). As is well known, doping of high-valent $\mathrm{Nb}^{5+}$ and $\mathrm{Sn}^{4+}$ into the $\mathrm{Fe}_{2} \mathrm{O}_{3}$ lattice would enhance its n-type character by converting some $\mathrm{Fe}^{3+}$ into $\mathrm{Fe}^{2+}$ for charge compensation. ${ }^{23}$ Electrochemical reduction during cathodic scanning of the activation process produces a sub-stoichiometric metal oxide by introduction of $V_{\mathrm{O}}{ }^{24}$ which is actually +2 charged and thus contributes to the ntype conductivity in the same manner as the metal doping. ${ }^{25}$ It is difficult to maintain them near the surface because of contact with the electrolyte and water oxidation reaction during the anodic scanning, but they are well preserved in the bulk. In particular the highly doped $\mathrm{Nb}, \mathrm{Sn}: \mathrm{Fe}_{2} \mathrm{O}_{3}$ NRs are favorable to preserve $\mathrm{Fe}^{2+}$ ions or $V_{\mathrm{O}}$ in the bulk because their strong n-type character would make more free electrons available in the hematite lattice to suppress re-oxidation.

In order to demonstrate validity of the proposed sequential redox activation process, we tried the reverse sequence of thrice anodic scanning first followed by thrice cathodic scanning. The corresponding XPS spectra show decreased intensity of Fe $2 p$ by only $25.2 \%$ (Fig. S11a $\dagger$ ), which is $\sim 60 \%$ that of Fe 2 p spectra in Fig. $3 \mathrm{a}_{1}$, indicating that the selective removal of $\mathrm{Fe}^{3+}$ ions from the surface is much less significant.

In addition, the satellite peak of $\mathrm{Fe}^{3+}$ at $719.3 \mathrm{eV}$ still has a significant intensity remaining in the etched sample, indicating formation of fewer $\mathrm{Fe}^{2+}$ ions or $V_{\mathrm{O}}$ in the bulk. As a result, the corresponding PEC performance of the $\mathrm{Nb}, \mathrm{Sn}: \mathrm{Fe}_{2} \mathrm{O}_{3}$ photoanode activated by the reversed sequence exhibits only $39.8 \%$ improved photocurrent and $30 \mathrm{mV}$ shift of $V_{\text {on }}$ (Fig. S11b $\dagger$ ). Therefore, cathodic scanning first and subsequent anodic scanning are essential for the efficient activation process, leading to significantly enhanced PEC performance, i.e. 62.3\% higher photocurrent and $\sim 70 \mathrm{mV}$ shift of $V_{\text {on }}$ as in Fig. $4 \mathrm{a}$. Generally, the same element ions with different valences in equivalent points of a crystal lattice lead to a jumping mechanism for electronic conductivity ${ }^{26}$ as in the present case of $\mathrm{Nb}, \mathrm{Sn}: \mathrm{Fe}_{2} \mathrm{O}_{3} \mathrm{NRs}$.

Nyquist plots of electrochemical impedance spectroscopy (EIS) in Fig. 4b for both activated and pristine electrodes are characterized by two semicircles at high $\left(f_{\mathrm{H}}, 100-2 \mathrm{kHz}\right)$ and low $\left(f_{\mathrm{L}}, 2000-0.1 \mathrm{~Hz}\right)$ frequencies. They could be fitted by a simple equivalent model of two circuits (inset), which was first discussed by Hamann and Bisquert. ${ }^{27,28}$ The loop at $f_{\mathrm{H}}$ usually reflects the information of charge carriers in bulk hematite $\left(R_{\mathrm{ct}}\right)$ $C_{\text {bulk }}$ ), while the loop at $f_{\mathrm{L}}$ represents the information about the hematite/electrolyte interface $\left(R_{\text {trap }} / C_{\text {trap }}\right)$. The fitting results are summarized in Table S2. $\dagger$ The sheet resistance of $R_{\mathrm{S}}$ (involving the electrolyte, external contact, and FTO resistances) is small and essentially constant. ${ }^{29}$ The resistance $R_{\mathrm{ct}}$ is reduced by $33.4 \%$ by the activation treatment, probably by improved conductivity due to generation of more $\mathrm{Fe}^{2+}$ ions or $V_{\mathrm{O}}$ in the bulk of Nb,Sn: $\mathrm{Fe}_{2} \mathrm{O}_{3}$ NRs. More importantly, $R_{\text {trap }}$ decreases significantly by $50.7 \%$ by selective removal of defects, unsaturated covalent bonds, and adsorbates on the surface while 
maintaining substantial $\mathrm{Nb}-\mathrm{O}$ and $\mathrm{Sn}-\mathrm{O}$ bonds. Moreover, the capacitances of $C_{\text {bulk }}$ and $C_{\text {trap }}$ increase considerably after the activation.

Mott-Schottky plots were acquired from bulk capacitance values of EIS spectra, which gave the flat band potential $\left(E_{\mathrm{FB}}\right.$, the intercept values on the $X$-axis) and the donor density $\left(N_{\mathrm{D}}\right.$, inversely proportional to the slopes). In Fig. $4 \mathrm{c}$, the electrochemical activation gives $18.1 \%$ increase of $N_{\mathrm{D}}$ and a positive shift of $E_{\mathrm{FB}}$ from 0.41 to $0.43 \mathrm{~V}_{\mathrm{RHE}}$, which are consistent with the reported values of hematite..$^{30}$ The increased $N_{\mathrm{D}}$ must be related to generation of more $\mathrm{Fe}^{2+}$ ions or $V_{\mathrm{O}}$, in agreement with the above XPS/EIS results and a previous report for formation of $\mathrm{Fe}_{3} \mathrm{O}_{4}$ from $\mathrm{Fe}_{2} \mathrm{O}_{3}$ by electrochemical introduction of $\mathrm{Fe}^{2+}$ ions. $^{31}$

On the surface of hematite, a range of different trap states including $V_{\mathrm{O}}$, crystal defects, and hole accumulation sites $(\mathrm{Fe}=$ O) are proposed to be detrimental to PEC efficiency. As demonstrated above, there exist more $\mathrm{Nb}$ and $\mathrm{Sn}$ elements on the surface of $\mathrm{Nb}, \mathrm{Sn}: \mathrm{Fe}_{2} \mathrm{O}_{3}$ NRs after the activation, which would selectively passivate such states and consequently contribute to the enhanced photocurrent density and/or cathodically shifted $V_{\text {on }}$. Indeed, a very thin layer of $\mathrm{Ta}_{2} \mathrm{O}_{5}$ was demonstrated to have a good passivation effect on the hematite surface. $^{32}$ Likewise, the mostly remaining $\mathrm{Nb}-\mathrm{O}$ and $\mathrm{Sn}-\mathrm{O}$ bonds on the hematite surface after activation should have a similar beneficial effect. In addition, they also contribute significantly to the stability of the photoanode because of their high bond energies. Indeed, Fig. 4d shows clearly enhanced stability after the activation treatment, maintaining $95 \%$ of initial photocurrent generation after $5 \mathrm{~h}$ of PEC water oxidation, whereas the pristine photoanode maintains only $79 \%$ of the initial activity. The results also confirm that the activated state remains stable and irreversible during the PEC water oxidation.

Steady-state photoluminescence spectroscopy (PL) and timeresolved PL were used to monitor the charge transfer dynamics in the activated $\mathrm{Nb}, \mathrm{Sn}: \mathrm{Fe}_{2} \mathrm{O}_{3}$ photoanode. Generally, bulk $\mathrm{Fe}_{2} \mathrm{O}_{3}$ exhibits little PL because of serious nonradiative recombination. However, its PL is highly dependent on surface quality, especially on surface trap density. ${ }^{33}$ Therefore, PL would be enhanced when surface states are even partially eliminated by the activation process. The PL spectra of both activated and pristine Nb,Sn: $\mathrm{Fe}_{2} \mathrm{O}_{3}$ NRs in Fig. 5a show a weak emissionbeginning peak at $575 \mathrm{~nm}(2.15 \mathrm{eV})$ and a relatively strong emission peak at $615 \mathrm{~nm}$, which are consistent with previous reports of hematite. ${ }^{34}$ In addition, the bare FTO treated under the same conditions as $\mathrm{Nb}, \mathrm{Sn}: \mathrm{Fe}_{2} \mathrm{O}_{3}$ synthesis shows no PL signal in the measured range (Fig. S12†). The enhanced PL of the activated sample is strong evidence that a part of surface trap states is passivated in the electrochemical activation process by selective removal of defects and retaining more $\mathrm{Nb}-$ $\mathrm{O}$ and $\mathrm{Sn}-\mathrm{O}$ bonds.

In time-resolved PL (Fig. 5b), the activated sample shows a little higher tailing relative to that of the pristine sample, indicating that the activated sample has a longer charge carrier lifetime. The measured charge carrier lifetime denotes the time that takes for electron-hole pairs to decay to $1 / \mathrm{e}$ by radiative recombination. ${ }^{35}$ Therefore, the longer lifetime means a slower
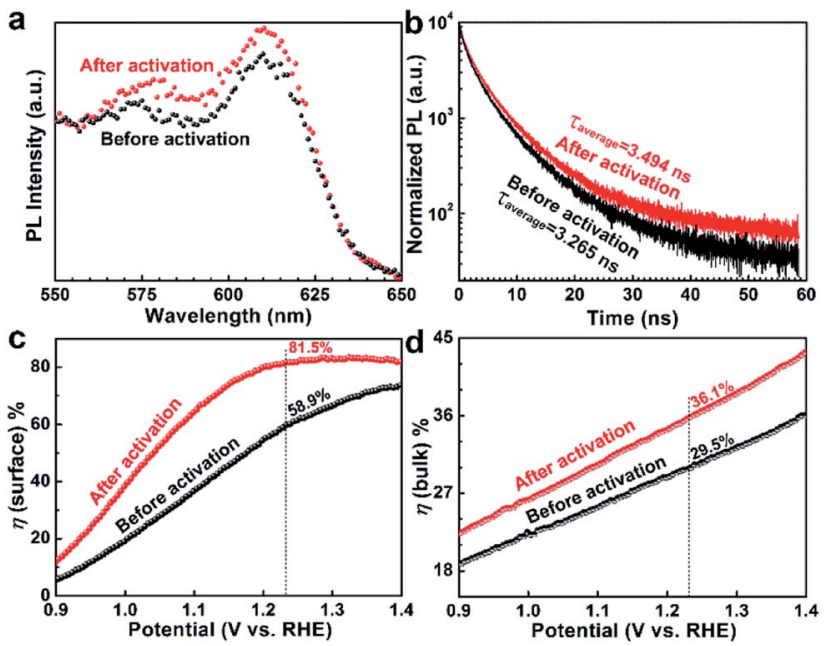

Fig. 5 Steady state PL spectra (a), time-resolved PL spectra (b), surface charge separation efficiency, $\eta_{\text {surface }}$ (c), and bulk charge separation efficiency, $\eta_{\text {bulk }}$ (d) of the $\mathrm{Nb}, \mathrm{Sn}: \mathrm{Fe}_{2} \mathrm{O}_{3}$ nanorod photoanode before and after the activation treatment.

recombination of the charge carriers. From the fitting of the PL decay kinetics, the amplitude weighted average lifetimes were $\tau_{\text {avg }}=3.494 \mathrm{~ns}$ for the activated sample and $\tau_{\text {avg }}=3.265 \mathrm{~ns}$ for the pristine sample (other parameters in Table S $3 \uparrow$ ). In general, the short PL lifetime of hematite is attributed to the fast recombination between holes and electrons, which results from its short hole diffusion length. However, the activated sample shows $7 \%$ longer lifetime than that of the pristine sample, which must be related to the surface passivation effect by selective removal of surface trap sites and more $\mathrm{Nb}-\mathrm{O}$ and $\mathrm{Sn}-\mathrm{O}$ bonds retained on the surface by the activation process.

The surface $\left(\eta_{\text {surface }}\right)$ and bulk $\left(\eta_{\text {bulk }}\right)$ charge separation efficiencies were determined by comparing photo-oxidation currents of water and a hole scavenger $\left(0.5 \mathrm{M} \mathrm{H}_{2} \mathrm{O}_{2}\right)$ in the same electrolyte $(1 \mathrm{M} \mathrm{KOH})$. The detailed procedures are shown in Fig. S13. $\uparrow$ The $\eta_{\text {surface }}$ represents the fraction of holes at the interface that is successfully injected to the electrolyte to oxidize water without recombination on the semiconductor surface, while $\eta_{\text {bulk }}$ is the fraction of holes that reach the interface of the semiconductor/electrolyte without recombination in the bulk. As in Fig. $5 \mathrm{c}, \eta_{\text {surface }}$ improves from $58.9 \%$ to $81.5 \%$ at $1.23 \mathrm{~V}_{\mathrm{RHE}}$ after the electrochemical activation, indicating that the surface properties of hematite nanorods have been significantly improved by removal of surface trap sites and surface passivation by more $\mathrm{Nb}-\mathrm{O}$ and $\mathrm{Sn}-\mathrm{O}$ bonds retained. The $\eta_{\text {bulk }}$ also improves from $29.5 \%$ to $36.1 \%$ at $1.23 \mathrm{~V}_{\mathrm{RHE}}$ upon the electrochemical activation (Fig. 5d), indicating that the generated $\mathrm{Fe}^{2+}$ ions or $V_{\mathrm{O}}$ effectively enhances the electrical conductivity in the bulk of hematite. These results further support the aforementioned discussion on the effect of the activation treatment.

\subsection{Application to other photoanodes}

In order to test the general applicability of our electrochemical activation process, it was applied to two related materials. The first was $\mathrm{Nb}, \mathrm{Sn}: \mathrm{Fe}_{2} \mathrm{O}_{3} @ \mathrm{FeNbO}_{4}$ core-shell heterojunction NRs 
that we studied in our previous work. ${ }^{13}$ As shown in Fig. S14, $\uparrow$ the activation of the core-shell heterojunction shows very limited (only 6.2\%) increase of photocurrent. The other repeated samples show similar behaviour (Table $\mathrm{S} 4 \dagger$ ). Because of high stability of the $\mathrm{FeNbO}_{4}$ shell and strong n-type character of the core, we cannot take advantage of the beneficial effects of selective removal of the surface components to passivate surface trap sites and introduction of $V_{\mathrm{O}} / \mathrm{Fe}^{2+}$ in lattices to increase the conductivity. The second test material was only Sndoped hematite, which showed marked effects of the activation treatment. As shown in Fig. S15, $\uparrow$ the photocurrent is improved by $44.4 \%$, (from 1.24 to $1.79 \mathrm{~mA} \mathrm{~cm}^{-2}$ at $1.23 \mathrm{~V}_{\mathrm{RHE}}$ under 1 sun condition), which is comparable to the present $\mathrm{Nb}, \mathrm{Sn}: \mathrm{Fe}_{2} \mathrm{O}_{3}$ photoanode $(62.3 \%$ increase). The other activated samples (Table $\mathrm{S} 5 \dagger$ ) also show reproducible results and the same tendency with the $\mathrm{Nb}, \mathrm{Sn}: \mathrm{Fe}_{2} \mathrm{O}_{3}$ electrode (higher extent of improvement on the poorer pristine sample). This is reasonable because the poor pristine samples (prepared under the same conditions) usually have more surface states, and most of them would be passivated by the activation. The results confirm that our activation strategy is applicable to improve the activity of hematite-based photoanodes in general, but is not very effective for hematite with a stable protective layer, for which the selective removal of the surface components is difficult.

\section{Conclusions}

In summary, we have demonstrated a simple and effective electrochemical activation process that improves the PEC water oxidation performance of the $\mathrm{Nb}, \mathrm{Sn}: \mathrm{Fe}_{2} \mathrm{O}_{3}$ photoanode in terms of photocurrent density, onset potential, and stability. The activation process involves initial thrice cathodic scanning followed by thrice anodic scanning, which makes three main modifications of hematite. First, it selectively removes the surface components to different extents endowing the hematite surface with fewer defects and richer $\mathrm{Nb}-\mathrm{O}$ and $\mathrm{Sn}-\mathrm{O}$ bonds and thus passivates the surface trap states. The surface passivation effect also enhances the PEC stability of the photoanode. Finally, more $\mathrm{Fe}^{2+}$ ions or $V_{\mathrm{O}}$ is generated in the bulk of hematite to enhance its conductivity. These changes in the bulk and on the surface of hematite are responsible for the greatly enhanced PEC performance by improving charge separation efficiencies both on the surface $\left(\eta_{\text {surface }}\right)$ and in the bulk $\left(\eta_{\text {bulk }}\right)$. The electrochemical activation strategy proposed here could be extended to a number of other metal oxide semiconductors including $\mathrm{WO}_{3}, \mathrm{TiO}_{2}, \mathrm{BiVO}_{4}$ and $\mathrm{ZnO}$ for significantly improved PEC water splitting activity.

\section{Experimental section}

\subsection{Fabrication of ultrathin FeOOH nanorods on FTO substrates}

Conductive FTO substrates (PECTM 8, 6-9 $\Omega$, Pilkington) of 25 $\times 50 \mathrm{~mm}^{2}$ were cleaned by ultrasonication for $30 \mathrm{~min}$ in detergent, ethanol, and acetone, respectively. The FTO surface becomes sufficiently hydrophilic by this cleaning process. The $\mathrm{FeOOH}$ nanorods grow on FTO at $100{ }^{\circ} \mathrm{C}$ for $2 \mathrm{~h}$ using $100 \mathrm{~mL}$ of an aqueous solution containing $4.0 \mathrm{~g} \mathrm{FeCl}_{3} \cdot 6 \mathrm{H}_{2} \mathrm{O}$ (Sigma Aldrich, $\geq 99 \%$ ), $200 \mu \mathrm{L} \mathrm{HNO}_{3}$ (Sigma Aldrich, 70\%) and $8.4 \mathrm{~g}$ $\mathrm{NaNO}_{3}$ (Sigma Aldrich, $\geq 99 \%$ ). The obtained yellow-colored $\mathrm{FeOOH}$ nanorod film after cooling down was rinsed with abundant deionized water.

\subsection{Hybrid microwave annealing (HMA)}

The prepared samples $\left(12.5 \times 12.5 \mathrm{~mm}^{2}\right)$ were put on graphite powder (60 $\mathrm{mL}$ graphite as a susceptor) in a Pyrex beaker (100 $\mathrm{mL})$ and treated in a microwave oven $(2.45 \mathrm{GHz}, 1000 \mathrm{~W})$ for 2 $\min (100 \%$ power).

\subsection{Physical characterization}

The morphology of the samples was acquired using a fieldemission scanning electron microscope (FESEM-S4800, HITACHI). High-angle annular dark-field scanning transmission electron microscopy (HAADF-STEM) images and corresponding electron energy loss spectroscopy (EELS) mapping were taken using a FEI Titan3 G2 60-300 microscope equipped with a double-sided Cs corrector operating at $200 \mathrm{kV}$. High resolution TEM (HRTEM) images in bright field were obtained using a Cscorrected high-resolution transmission electron microscope (JEOL, JEM-2100F, $200 \mathrm{kV}$ ). X-ray diffraction (XRD) spectra were acquired using a PW3040/60 X'per PRO, PANalytical, using Cu$\mathrm{K} \alpha(\lambda=1.54056 \AA)$ radiation, an accelerating voltage of $40 \mathrm{kV}$ and a current of $30 \mathrm{~mA}$. Ultraviolet-visible absorbance was obtained using a UV-vis spectrometer (UV-2401PC, Shimadzu). Xray photoelectron spectroscopy (XPS) was carried out on a Thermo-Fisher machine (XPS, ESCALAB 250XI) using an Al Ka source. Inductively coupled plasma optical emission spectrometry (ICP-OES) was obtained on a Varian machine (700-ES). Steady state photoluminescence (PL) measurements were conducted on a spectrofluorometer (FLS920) with an excitation wavelength of $450 \mathrm{~nm}$ using a $450 \mathrm{~W}$ xenon lamp excitation source and a photomultiplier tube detector. Time-resolved PL spectra were measured using a time-correlated single-photon counting (TCSPC) setup (FluoTime 300). The excitation source was a $450 \mathrm{~nm}$ continuous-wave and pulsed diode laser head (LDH-D-C-450) coupled with a laser diode driver (PDL 820) with a pulse width of $<70 \mathrm{ps}$ and a repetition rate of $196 \mathrm{kHz}$ to 40 MHz. Each exponential decay curve was deconvoluted using the associated fitting software (FluoFit) to calculate the time constant associated with each curve.

\section{4 (Photo)electrochemical measurements}

All (photo)electrochemical measurements were conducted on a potentiostat (IviumStat, Ivium Technologies) in a three electrode system using a hematite photoanode, $\mathrm{Ag} / \mathrm{AgCl}(3 \mathrm{M} \mathrm{NaCl})$, and Pt mesh as working, reference, and counter electrodes, respectively, in $1 \mathrm{M} \mathrm{KOH}$ electrolyte under 1-sun condition (100 $\mathrm{mW} \mathrm{cm}^{-2}$ ) using a solar simulator (91160, Oriel) with an AM 1.5 $\mathrm{G}$ filter. Note that the exposed surface area of all the prepared photoanodes was $1 \mathrm{~cm}^{2}$ and the electrolyte was slowly stirred during the measurements. All the potentials vs. the $\mathrm{Ag} / \mathrm{AgCl}$ reference electrode were converted to the potentials $v s$. the reversible hydrogen electrode (RHE) according to the Nernst 
equation: $E_{\mathrm{RHE}}=E_{\mathrm{Ag} / \mathrm{AgCl}}+0.059 \mathrm{pH}+E_{\mathrm{Ag} / \mathrm{AgCl}}^{\mathrm{o}}\left(E_{\mathrm{Ag} / \mathrm{AgCl}}^{\mathrm{o}}=0.1976\right.$ at $25{ }^{\circ} \mathrm{C}$ ). The potential was swept in the range of 0.5-1.8 $\mathrm{V}_{\mathrm{RHE}}$ with a scanning rate of $20 \mathrm{mV} \mathrm{s}^{-1}$. Electrochemical impedance spectroscopy (EIS) was carried out at $1.23 \mathrm{~V}_{\mathrm{RHE}}$ under simulated 1-sun condition with a frequency range of $0.1 \mathrm{~Hz}$ to $100 \mathrm{kHz}$ and the data were fitted by Z-view software. Mott-Schottky plots were obtained by sweeping a 0.1-1.0 $\mathrm{V}_{\mathrm{RHE}}$ range with an AC frequency of $1000 \mathrm{~Hz}$ under dark conditions. The charge carrier density, $N_{\mathrm{D}}$, can be extracted and is inversely proportional to the slope as shown in eqn (1):

$$
\left(\frac{A_{\mathrm{S}}}{C_{\text {bulk }}}\right)^{2}=\frac{2}{q \varepsilon_{\mathrm{r}} \varepsilon_{0} N_{\mathrm{D}}}\left(V-E_{\mathrm{FB}}-\frac{k_{\mathrm{B}} T}{q}\right)
$$

with $\left(\frac{A_{\mathrm{S}}}{C_{\mathrm{bulk}}}\right)$ being the surface area-corrected space charge capacitance, $V$ the applied potential, $E_{\mathrm{FB}}$ the flat band of the electrode, $k_{\mathrm{B}}=1.38 \times 10^{-23} \mathrm{~J} \mathrm{~K}^{-1}, T=298 \mathrm{~K}, q=1.602 \times 10^{-19}$ $\mathrm{C}, \varepsilon_{0}=8.85 \times 10^{-12} \mathrm{C}^{2} \mathrm{~J}^{-1} \mathrm{~m}^{-1}$, and $\varepsilon_{\mathrm{r}}=32$ for hematite.

\section{Conflicts of interest}

There are no conflicts to declare.

\section{Acknowledgements}

This work was supported by the Climate Change Response Project (NRF-2019M1A2A2065612 and 2015M1A2A2074663), the Basic Science Grant (NRF-2018R1A2A1A05077909), Korea Centre for Artificial Photosynthesis (KCAP, No. 2009-0093880), Next Generation Carbon Upcycling Project (2017M1A2A2042517), and the Korea-China Key Joint Research Program (2017K2A9A2A11070341) funded by MSIP, and Project No. 10050509 and KIAT N0001754 funded by MOTIE of Republic of Korea.

\section{References}

1 K. Sivula and R. van de Krol, Semiconducting materials for photoelectrochemical energy conversion, Nat. Rev. Mater., 2016, 1, 15010.

2 L. M. Carneiro, S. K. Cushing, C. Liu, Y. Su, P. Yang, A. P. Alivisatos and S. R. Leone, Excitation-wavelengthdependent small polaron trapping of photoexcited carriers in $\alpha-\mathrm{Fe}_{2} \mathrm{O}_{3}$, Nat. Mater., 2017, 16, 819.

3 H. Dotan, O. Kfir, E. Sharlin, O. Blank, M. Gross, I. Dumchin, G. Ankonina and A. Rothschild, Resonant light trapping in ultrathin films for water splitting, Nat. Mater., 2013, 12, 158.

4 H. Zhang, J. H. Kim, J. H. Kim and J. S. Lee, Engineering Highly Ordered Iron Titanate Nanotube Array Photoanodes for Enhanced Solar Water Splitting Activity, Adv. Funct. Mater., 2017, 27, 1702428.

5 Z. Wang, X. Mao, P. Chen, M. Xiao, S. A. Monny, S. Wang, M. Konarova, A. Du and L. Wang, Understanding the Roles of Oxygen Vacancies in Hematite-Based Photoelectrochemical Processes, Angew. Chem., Int. Ed., 2019, 58, 1030.
6 J.-W. Jang, C. Du, Y. Ye, Y. Lin, X. Yao, J. Thorne, E. Liu, G. McMahon, J. Zhu, A. Javey, J. Guo and D. Wang, Enabling unassisted solar water splitting by iron oxide and silicon, Nat. Commun., 2015, 6, 7447.

7 J. Y. Kim, D. H. Youn, K. Kang and J. S. Lee, Highly Conformal Deposition of an Ultrathin FeOOH Layer on a Hematite Nanostructure for Efficient Solar Water Splitting, Angew. Chem., Int. Ed., 2016, 55, 10854-10858.

8 W. Li, S. W. Sheehan, D. He, Y. He, X. Yao, R. L. Grimm, G. W. Brudvig and D. Wang, Hematite-Based Solar Water Splitting in Acidic Solutions: Functionalization by Monoand Multilayers of Iridium Oxygen-Evolution Catalysts, Angew. Chem., Int. Ed., 2015, 54, 11428-11432.

9 D. Cao, W. Luo, J. Feng, X. Zhao, Z. Li and Z. Zou, Cathodic shift of onset potential for water oxidation on a $\mathrm{Ti}^{4+}$ doped $\mathrm{Fe}_{2} \mathrm{O}_{3}$ photoanode by suppressing the back reaction, Energy Environ. Sci., 2014, 7, 752-759.

10 Y. Yang, M. Forster, Y. Ling, G. Wang, T. Zhai, Y. Tong, A. J. Cowan and Y. Li, Acid Treatment Enables Suppression of Electron-Hole Recombination in Hematite for Photoelectrochemical Water Splitting, Angew. Chem., Int. Ed., 2016, 55, 3403-3407.

11 T. Li, J. He, B. Pena and C. P. Berlinguette, Curing BiVO4 Photoanodes with Ultraviolet Light Enhances Photoelectrocatalysis, Angew. Chem., Int. Ed., 2016, 55, 1769-1772.

12 S. Wang, P. Chen, J.-H. Yun, Y. Hu and L. Wang, An Electrochemically Treated $\mathrm{BiVO}_{4}$ Photoanode for Efficient Photoelectrochemical Water Splitting, Angew. Chem., Int. Ed., 2017, 56, 8500-8504.

13 H. Zhang, Y. K. Kim, H. Y. Jeong and J. S. Lee, A Few Atomic $\mathrm{FeNbO}_{4}$ Overlayers on Hematite Nanorods: MicrowaveInduced High Temperature Phase for Efficient Photoelectrochemical Water Splitting, ACS Catal., 2019, 9, 1289-1297.

14 H. Zhang, W. Y. Noh, F. Li, J. H. Kim, H. Y. Jeong and J. S. Lee, Three Birds, One-Stone Strategy for Hybrid Microwave Synthesis of Ta and Sn Codoped $\mathrm{Fe}_{2} \mathrm{O}_{3} @ \mathrm{FeTaO}_{4}$ Nanorods for Photo-Electrochemical Water Oxidation, Adv. Funct. Mater., 2019, 29, 1805737.

15 Y. R. Luo, Comprehensive handbook of chemical bond energies, CRC Press, Boca Raton, FL, 2007.

16 T. Yamashita and P. Hayes, Analysis of XPS spectra of $\mathrm{Fe}^{2+}$ and $\mathrm{Fe}^{3+}$ ions in oxide materials, Appl. Surf. Sci., 2008, 254, 2441-2449.

17 M. Huang, Y. Zhang, F. Li, Z. Wang, M. Alamusi, N. Hu, Z. Wen and Q. Liu, Merging of Kirkendall Growth and Ostwald Ripening: $\mathrm{CuO} @ \mathrm{MnO}_{2}$ Core-shell Architectures for Asymmetric Supercapacitors, Sci. Rep., 2014, 4, 4518.

18 P. Peerakiatkhajohn, J.-H. Yun, H. Chen, M. Lyu, T. Butburee and L. Wang, Stable Hematite Nanosheet Photoanodes for Enhanced Photoelectrochemical Water Splitting, Adv. Mater., 2016, 28, 6405-6410.

19 K. Vijayasankar, N. Y. Hebalkar, H. G. Kim and P. H. Borse, Controlled band energetics in Pb-Fe-Nb-O metal oxide composite system to fabricate efficient visible light photocatalyst, J. Ceram. Process. Res., 2013, 14, 557-562. 
20 Y. Ling, G. Wang, D. A. Wheeler, J. Z. Zhang and Y. Li, SnDoped Hematite Nanostructures for Photoelectrochemical Water Splitting, Nano Lett., 2011, 11, 2119-2125.

21 C. Du, X. Yang, M. T. Mayer, H. Hoyt, J. Xie, G. McMahon, G. Bischoping and D. Wang, Hematite-Based Water Splitting with Low Turn-On Voltages, Angew. Chem., Int. Ed., 2013, 52, 12692-12695.

22 Y. Lin, Y. Xu, M. T. Mayer, Z. I. Simpson, G. McMahon, S. Zhou and D. Wang, Growth of p-Type Hematite by Atomic Layer Deposition and Its Utilization for Improved Solar Water Splitting, J. Am. Chem. Soc., 2012, 134, 55085511.

23 V. M. Aroutiounian, V. M. Arakelyan, G. E. Shahnazaryan, G. M. Stepanyan, E. A. Khachaturyan, H. Wang and J. A. Turner, Photoelectrochemistry of semiconductor electrodes made of solid solutions in the system $\mathrm{Fe}_{2} \mathrm{O}_{3}$ $\mathrm{Nb}_{2} \mathrm{O}_{5}$, Sol. Energy, 2006, 80, 1098-1111.

24 G. Wang, Y. Yang, Y. Ling, H. Wang, X. Lu, Y.-C. Pu, J. Z. Zhang, Y. Tong and Y. Li, An electrochemical method to enhance the performance of metal oxides for photoelectrochemical water oxidation, J. Mater. Chem. A, 2016, 4, 2849-2855.

25 L. Liu, Z. Mei, A. Tang, A. Azarov, A. Kuznetsov, Q.-K. Xue and $\mathrm{X}$. Du, Oxygen vacancies: The origin of n-type conductivity in ZnO, Phys. Rev. B, 2016, 93, 235305.

26 S. Krupička, Physik der Ferrite und der Verwandten Magnetischen Oxide, Vieweg+Teubner Verlag, 1973.

27 B. Klahr, S. Gimenez, F. Fabregat-Santiago, T. Hamann and J. Bisquert, Water Oxidation at Hematite Photoelectrodes: The Role of Surface States, J. Am. Chem. Soc., 2012, 134, 4294-4302.

28 B. Klahr, S. Gimenez, F. Fabregat-Santiago, J. Bisquert and T. W. Hamann, Electrochemical and photoelectrochemical investigation of water oxidation with hematite electrodes, Energy Environ. Sci., 2012, 5, 7626-7636.

29 J. A. Glasscock, P. R. F. Barnes, I. C. Plumb and N. Savvides, Enhancement of Photoelectrochemical Hydrogen Production from Hematite Thin Films by the Introduction of Ti and Si, J. Phys. Chem. C, 2007, 111, 16477-16488.

30 S. D. Tilley, M. Cornuz, K. Sivula and M. Grätzel, LightInduced Water Splitting with Hematite: Improved Nanostructure and Iridium Oxide Catalysis, Angew. Chem., Int. Ed., 2010, 122, 6549-6552.

31 J. Wang, J. L. Waters, P. Kung, S. M. Kim, J. T. Kelly, L. E. McNamara, N. I. Hammer, B. C. Pemberton, R. H. Schmehl, A. Gupta and S. Pan, A Facile Electrochemical Reduction Method for Improving Photocatalytic Performance of $\alpha-\mathrm{Fe}_{2} \mathrm{O}_{3}$ Photoanode for Solar Water Splitting, ACS Appl. Mater. Interfaces, 2017, 9, 381-390.

32 M. Forster, R. J. Potter, Y. Yang, Y. Li and A. J. Cowan, Stable $\mathrm{Ta}_{2} \mathrm{O}_{5}$ Overlayers on Hematite for Enhanced Photoelectrochemical Water Splitting Efficiencies, ChemPhotoChem, 2018, 2, 183-189.

33 B. S. Zou and V. Volkov, Surface modification on timeresolved fluorescences of $\mathrm{Fe}_{2} \mathrm{O}_{3}$ nanocrystals, J. Phys. Chem. Solids, 2000, 61, 757-764.

34 F. Le Formal, N. Tétreault, M. Cornuz, T. Moehl, M. Grätzel and K. Sivula, Passivating surface states on water splitting hematite photoanodes with alumina overlayers, Chem. Sci., 2011, 2, 737-743.

35 J. Zheng, Y. Lyu, C. Xie, R. Wang, L. Tao, H. Wu, H. Zhou, S. Jiang and S. Wang, Defect-Enhanced Charge Separation and Transfer within Protection Layer/Semiconductor Structure of Photoanodes, Adv. Mater., 2018, 30, 1801773. 